\title{
Education Level, Young Migrant Labors and Social Exclusion
}

\author{
Hu Hong-wei ${ }^{\mathrm{a} 1}$, Cao Yang ${ }^{\mathrm{a} 2}$ \\ ${ }^{a}$ School of humanities and social sciences North China Electric Power University Baoding, China
}

\begin{abstract}
With rapid transition in China, young migrant labors begin to replace old ones. However, there are still many obstacles to the citizenization process of young migrant labors, and the main difficulty is social exclusion. From the perspective of social exclusion, this paper uses Logistic Regression, OLS and Ordered Probit to explore the education level's impact on young migrant labors' social exclusion. Eventually the research discovers that years of education, family burden, psychological gap and friend relationship have a significant effect, and the regression results are steady. Based on it, this paper proposes several ideas of strengthening rural education and reducing exclusion.
\end{abstract}

Index Terms: Education level; young migrant labors; social exclusion

(C) 2012 Published by MECS Publisher. Selection and/or peer review under responsibility of the International Conference on E-Business System and Education Technology

\section{Introduction}

According to the statistics, there are about 150 million migrant labors, $60 \%$ of whom are young migrant labors (hereinafter shortened as YMLs), about 100 million people. Solving the problems of YMLs is the key to solve the issue of migrant labors. The educational level of YMLs is much higher than the old ones. ${ }^{[1]}$ However, they still be excluded out on the edge of cities due to the restriction of strict two-dimension household register management system. ${ }^{[2]}$ They cannot have equivalent educational rights as citizens. Lack of accessible education opportunities makes them feel more seriously excluded by society in turn; this vicious circle obstructs their integrating into city life and imperils society stability. In the period from June of 2007 to May of 2010, frequent suicides and sudden deaths of Foxconn Group arguably exposed YMLs' serious situation. ${ }^{[3]}$

Under these critical circumstances, issued on 31 of January, the 2010 Chinese central first document, "China pledges new efforts to boost rural development", mentioned that deal with YMLs' problems with firm measures and citizenise the YMLs. ${ }^{[4]}$

Based on the above, our research aims at assessing the effect educational level has on YMLs' sense of social exclusion by conducting a micro data analysis from social exclusion perspective. In terms of research results, we pay more attention to the way of reducing sense of social exclusion such as primary education and skill training.

\footnotetext{
The study is supported by the project "Researches on public finance and medical insurance reform of urban residents"

* Corresponding author.

E-mail address: ${ }^{1}$ hutougao@ $126 . c o m,{ }^{2} \mathrm{CY} 112682663 @ 126 . c o m$
} 


\section{DATA AND VARIABLE DESCRIPTIPN}

The data this paper uses is from the survey of psychological stress of YMLs made by north China electric power university in July 2010. According to the concentration of distribution of YMLs, the survey, using stratified sampling, covers 452 YMLs in four provinces of northern, central and southern of China, and it has much information about social exclusion, education, work, psychology, families and so on. 500 copies of questionnaires were sent, but 452 valid copies were retrieved,. The effective rate of recovery was $90.4 \%$. Then we use Stata to analyze data.

According to the need of research, this paper chooses variables on Individual sociology characteristics, work, and psychology of YMLs, and describes them as the following.

We can see from table 1 and table 2 that $\mathrm{R}$ is an ordinal variable reflecting social exclusion, and its value ranges from 1 to 5, which means YMLs' sense of social exclusion is decreasing. About 18\% of YMLs feel relatively serious social exclusion, while about $10 \%$ believe they have no social exclusion. EY is an internal variable reflecting years of education, of which the average value is about 10.3 years, that is, most of them graduate from Junior school, and the highest reaches 20 years, which means YMLs' education level have been greatly improved than old ones, even a small fraction have college diplomas or above.

In table1, A is standing for age, whose average value of samples is about 25 years. The smallest is 18 years, and the biggest is 34 . $\mathrm{E}$ is an internal variable reflecting work experience, whose average value is 4.2 years. TL is an ordinal variable standing for technical level, which is improved from 1 to 4 . From description, we find YMLs' average technical level is about the primary. WH is an internal variable reflecting working hours, whose average value is 9.5 hours, that is, YMLs still work more than 8 hours per day. T (short for trade) is an ordinal variable, expressing the stability of work is enhanced from 1 to 3 , and from description we find the stability of YMLs' work is still relatively low. L is an ordinal variable ranging from 1 to 5, expressing amateur life is getting richer, and we find its average value is 2.8, less than median 3, so it means YMLs' amateur life is still boring. YMLs' average value of W(short for wage) is 1895 yuan, which is more than old migrant labors', but after further analysis, we find there are still a part of them have low income, lowest to 200 yuan. FB, which means the burden from economic life of the family, is an ordinal variable, representing family burden is decreasing from 1 to 5 . Because its average value is 2.7, YMLs still have heavier family burdens. G, which is used to measure YMLs' psychological discomfort after they step into society, ranges from 1 to 5, representing gap is decreasing. $\mathrm{F}$ which is used to measure whether YMLs have a better way to vent their emotions and a better social support network, is an ordinal variable ranging from 1 to 5, expressing relations with friends is getting better. We can find from its average value that most of the YMLs have good relations with their friends.

TABLE1. DESCRIPTIVE ANALYSIS OF VARIABLE

\begin{tabular}{cccccc}
\hline variable & Sample size & mean & Standard deviation & min & max \\
\hline R & 451 & 3.333 & 0.941 & 1 & 5 \\
A & 452 & 24.920 & 3.522 & 18 & 34 \\
EY & 429 & 10.296 & 3.084 & 2 & 20 \\
E & 439 & 4.205 & 2.732 & 0.080 & 15 \\
TL & 396 & 1.967 & 0.934 & 1 & 4 \\
T & 404 & 2.168 & 0.810 & 1 & 3 \\
WH & 434 & 9.458 & 1.878 & 3 & 15.500 \\
L & 450 & 2.829 & 0.958 & 1 & 5 \\
W & 408 & 1895.319 & 1194.660 & 200 & 12000 \\
FB & 451 & 2.727 & 0.961 & 1 & 5 \\
G & 451 & 2.539 & 1.009 & 1 & 5 \\
F & 444 & 3.813 & 0.814 & 1 & 5
\end{tabular}


TABLE2. DESCRIPTION OF SOCIAL EXCLUSION VARIABLE

\begin{tabular}{cccc|}
\hline Social exclusion $(\boldsymbol{R})$ & frequency & percentage & Cumulative percentage \\
\hline 1=very serious & 12 & 2.660 & 2.660 \\
2=serious & 69 & 15.300 & 17.960 \\
3=general & 171 & 37.920 & 55.880 \\
4=less exclusion & 155 & 34.370 & 90.240 \\
5=no exclusion & 44 & 9.760 & 100.000 \\
Total & 451 & 100.000 & \\
\hline
\end{tabular}

\section{EMPIRICAL ANALYSIS}

We'll analyze what affect YMLs' sense of social exclusion in this section, and use Logistic Regression, OLS and Ordered Probit to test the robustness of analysis results.

\section{A. A regression analysis of social exclusion}

As an important subjective indicator of YMLs' integrating with cities, $\mathrm{R}$ has the extremely vital significance. If YMLs don't feel social exclusion, it means they have a higher level of social integration, otherwise a lower level.

We take $\mathrm{R}$ as the dependent variable in Ordered Probit Regression, and results are shown in model5 of table3. Meanwhile, we take $\mathrm{R}$ as a continuous variable to make an OLS Regression, whose results are shown in model4. Besides, to improve the variability of R, the value of 'no exclusion' and 'less exclusion' is assumed to be 1 , while others to be 0 . Then we make a Logistic Regression, and the estimated coefficient, marginal value and Odds Ratio of corresponding regression results are listed in model1,2,3 respectively.

From regression results in table3, firstly we know age has an positive impact on YMLs' sense of social exclusion, that is, the older you're, the less social exclusion you'll feel, which is only significant in model 1, 2, 3. Secondly EY affects YMLs' sense of social exclusion significantly, that is, the more education you're received, the less social exclusion you'll feel, which is robust. The results in model1, 2, 3 show that TL has an positive impact on YMLs' sense of social exclusion, that is, the higher technical level you get, the less social exclusion you'll feel. Furthermore, FB affects YMLs' sense of social exclusion significantly, that is, the heavier burden you have, the less social exclusion you'll feel. Besides, the bigger gap between ideal and reality you face, the more social exclusion you'll feel. Finally, F affects YMLs' sense of social exclusion significantly, that is, the better friend relationship you have, the less social exclusion you'll feel.

It's worth noting that wage doesn't affect YMLs' sense of social exclusion significantly, nor do other variables related to work like WH, T, L, etc. It's proved again that what mainly affect YMLs' sense of social exclusion is some factors directly related to personal abilities, life and families, like years of education, family burdens, psychological gap and relations with friends. 
TABLE3. REGRESSION ANALYSIS OF SOCIAL EXCLUSION FACTORS

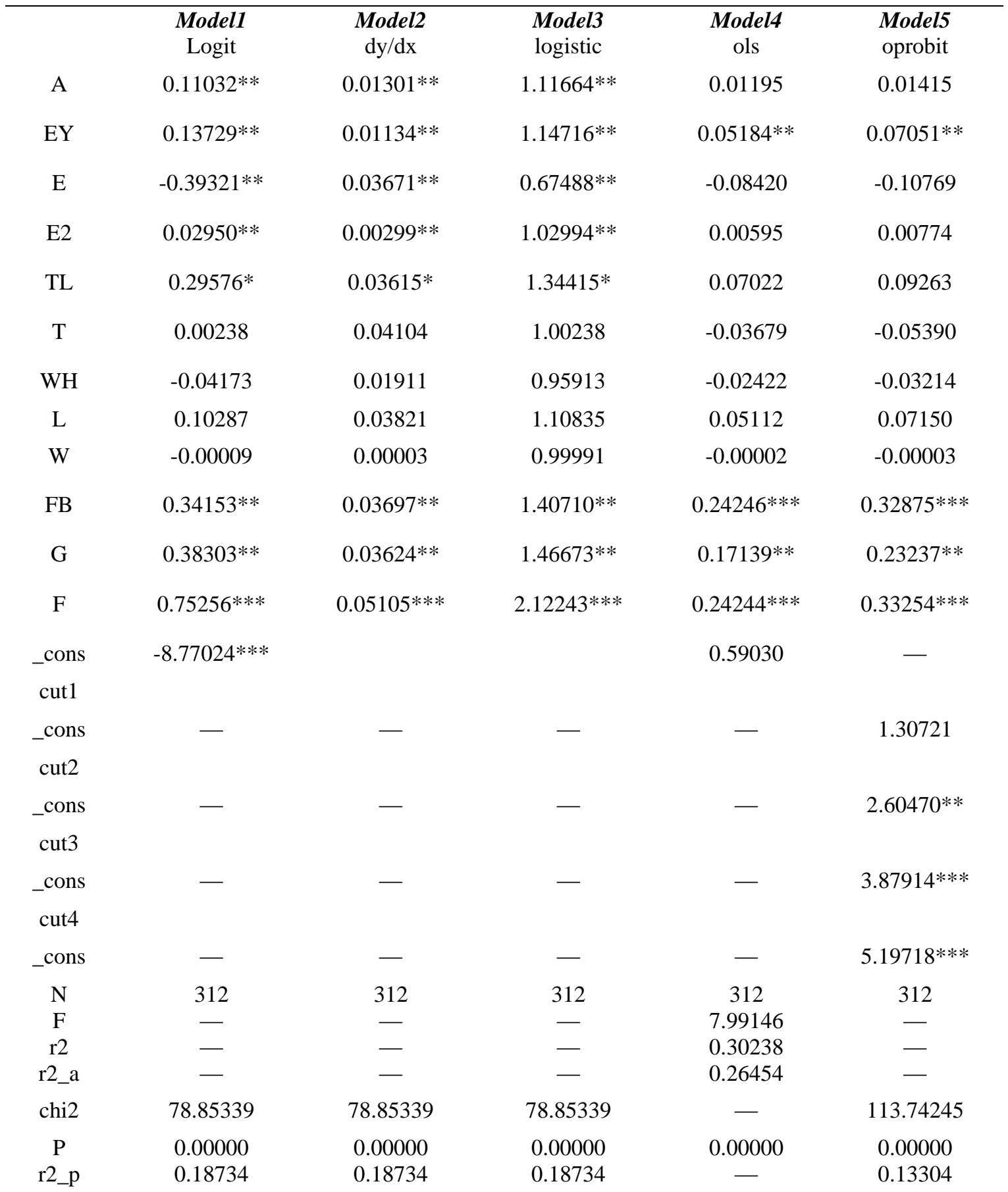


explanation: $1 .^{*} p<0.1,{ }^{* *} p<0.05,{ }^{* * *} p<0.012$. Model2 estimates the marginal value, of which the dummy variable is probability differences between y being 1 and y being 0.3 . Model 3 estimates relative Odds Ratio. 4. Ordinal variables in regression are seen as interval variables.

Besides, regression results of E aren't significant in model4 and model5., but regression coefficients in all the models are positive first, and then negative, like an inverted "U"-type, which means the first time YMLs step into cities, they feel serious social exclusion, however, as their work experience increasing to a certain degree, they feel less social exclusion.

\section{B. ROC test}

We test the regression results further by ROC and sensitive graph. ROC curve is used to measure the fitting effect of models. It can be seen from the figure below that the identification level of models is about 0.8 , showing the identification status of models is good. The sensitive graph reflects the regularity of sensitivity and specificity changing with the probability threshold, and it can be seen as the reference to choose the probability threshold.

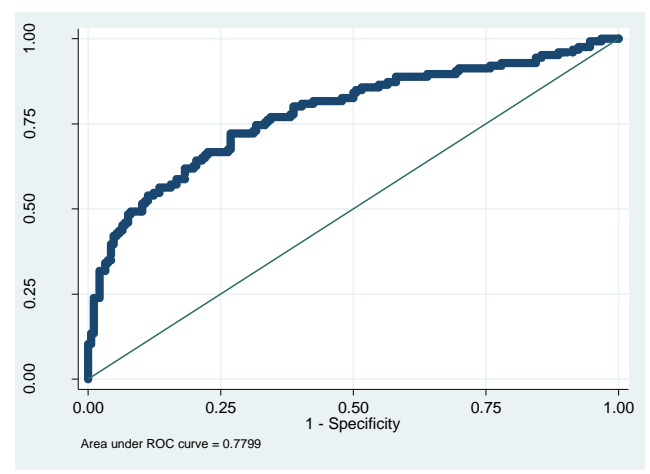

Figure1-a ROC curve of social exclusion

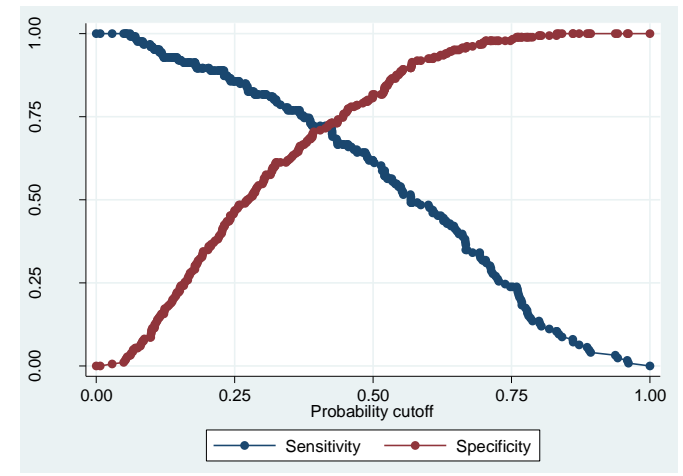

Figure1-b Sensitive graph of social exclusion

\section{CONCLUSIONS AND REFLECTIONS}

\section{A. Conclusions}


By making a conclusion about the results of the empirical research above, we can find:

1) The proportion of YMLs' sense of social exclusion is high. $18 \%$ of them thought they were excluded from the city seriously.

2) Compared with their older pioneers, YMLs are notably richer in knowledge and skills. However, their spare time is relatively scarce than working time. Many live a boring life. They have to shoulder heavy burdens of their families. They felt a huge gap after going into cities.

3) From the empirical analysis, we find sense of social exclusion is notably affected by educational level, family burdens, psychological gap and relations with friends. The result is robust. A higher education level, a lighter family burden, a less feeling of psychological gap and a better friendship lead to a less sense of social exclusion.

4) What needs to be noted is, the sense of social exclusion is not notably affected by factors concerning work, such as working time, wage and trade, etc. It certainly shows, from another aspect, that YMLs' working conditions (including work time, income, position, etc.) are greatly improved. Meanwhile, the condition of employment in cities is not satisfying. A large number of people can't find a job and their financial conditions are bad. So considerable YMLs hold an optimistic attitude that their working conditions are not much worse than those of citizens. Factors about working are no longer the causes of social exclusion.

\section{B. Reflections}

Based on the conclusion above, in order to reduce young migrant labors' social exclusion, firstly we should put emphasis on the constructions of rural education. Though YMLs receive higher level education than old migrant labors, they still lag behind their counterparts in cities. "According to the statistics, actual situation of educational level among cities, towns and rural areas is that proportion of educational level above junior college is 0.91:1.01:1, senior school is 4:3:1, junior school is 0.91:1.01:1, primary school is 0.37:0.55:1. ${ }^{,[5]}$ Accroding to it, central and local governments should implement rural education system, reconstruct the lopsided education system, inject more investment into high school and above, guarantee the right to education, and relocate the education resources in rural areas. Moreover, governments should act as leading roles and gather social resources to set up more professional schools which provide skill trainings for YMLs and give a specific skill for YMLs. Besides, there're some other steps we can take, such as paying more attention to psychological counseling and assisting of YMLs, protecting YMLs' basic conditions of working and learning, strengthening the construction of YMLs' social network ${ }^{[6]}$ and accelerating social integration. ${ }^{[7]}$

\section{Acknowledgment}

This study is supported by the project "Researches on public finance and medical insurance reform of urban residents".

\section{References}

[1] Yan Ting. “A dream city: young migrant labors' plight and future,” J. Contemporary Party Members, 2010 (4).( in Chinese)

[2] Gore, C. (1995a). What is special about a "social exclusion" approach? In Gerry Rodgers, Charles Gore and Jose B. Figueiredo (eds.). Social exclusion: Rhetoric, Reality and responses. (39-55). International Labor Organization (International Institue for Labor Studies).

[3] Hu Ting, "An analysis of young migrant labors' development confusion from a series of jump events in Foxconn," J. Law And Society, 2010 (23).(in Chinese)

[4] Wang Feng, Su Bei. "Young migrant labors' road to city---migrant labors' transformation needs institutional innovation," J. Talent Development, 2010 (5).(in Chinese)

[5] Wang Yi-yu, Wang Min-sheng, "Social education: an effective way to solve the problem of young migrant labors' social exclusion,” J. Adult Education, 2008 (4).(in Chinese) 
[6] Clare. "Poverty eradication and social integration: Britain's position," J. International Social Science: Chinese version, 2000 (4).( in Chinese)

[7] Lin Nan, Social capital---a theory about social action and structure, Century Group: Shanghai People's Publishing House, 2005, pp. 37-39.(in Chinese) 